\title{
OFICINAS DE ITALIANO E CRIOULO HAITIANO PARA TODOS: LÍNGUAS ADICIONAIS EM UM Centro Integrado de EduCAÇÃo DE JoVENS E ADULTOS
}

\section{Italian and Haitian Creole Workshops for Everyone: Additional Languages in an Integrated Center for Youth and Adult Education}

\author{
Laboratori di italiano e creolo haitiano per \\ tutti: lingue aggiuntive in un Centro Integrato di \\ Educazione di Giovani e Adulti
}

\author{
Daniela Aparecida Vieira* \\ Cristiane Maria Coutinho Fialho* *
}

RESUMO: Este artigo tem como objetivo apresentar o Centro Integrado de Educação de Jovens e Adultos (CIEJA) Perus I - instituição educacional da rede pública municipal de São Paulo (SP) - e duas atividades extracurriculares desenvolvidas nessa escola: as oficinas de italiano e de crioulo haitiano. Visando a atingir esse objetivo, primeiramente, discorremos sobre tal instituição, cujas práticas de ensino são fortemente embasadas pelos postulados de Paulo Freire (1974, 1996), autor que defende a ideia de que a educação é um direito que deve ser garantido a todos. Posteriormente, abordamos o funcionamento dessas atividades extracurriculares, concentrando-nos nas oficinas de italiano e crioulo haitiano como línguas adicionais. Tais oficinas são espaços públicos e coletivos de construção colaborativa de conhecimentos e reflexões críticas sobre essas línguas e suas respectivas culturas, o que permite aos participantes dessas atividades extracurriculares refletir, também, sobre a sua própria língua e a sua própria cultura. Baseando-nos nos postulados desse importante educador brasileiro, é possível dizer que essas oficinas são consideradas, de certa maneira, uma medida de justiça social, pois são públicas e gratuitas e têm como principal escopo a deselitização do ensino-aprendizagem de línguas adicionais.

\footnotetext{
*Docente - Centro Integrado de Educação de Jovens e Adultos (CIEJA) Perus I - São Paulo-SP

daniela.apvieira@yahoo.com.br (ORCID: 0000-0002-1197-7429)

**Docente - Centro Integrado de Educação de Jovens e Adultos (CIE-

JA) Perus I - São Paulo-SP

cristianemariafialho@gmail.com (ORCID: 0000-0002-1200-4565)

DOI: http://dx.doi.org/10.11606/issn.2238-8281.v0i42p158-175
}

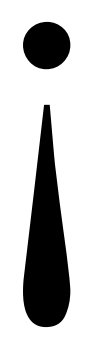


PALAVRAS-CHAVE: Educação de Jovens e Adultos; Escola pública; Italiano como língua adicional; Crioulo haitiano como língua adicional.

ABSTRACT: This article aims to present the Integrated Center for Youth and Adult Education (CIEJA) Perus I - a municipal public school of São Paulo (SP) - and two extracurricular activities developed in this school: the Italian and Haitian Creole workshops. In order to achieve this goal, firstly, we have presented this institution, whose teaching practices are strongly based on Paulo Freire's postulates (1974), an author who defends the idea that education is a right that should be guaranteed to everyone. Secondly, we have approached the functioning of these extracurricular activities, focusing on the Italian and Haitian Creole workshops as additional languages. These workshops are public and collective spaces for collaborative construction of knowledge and critical reflections on these languages and their respective cultures, which allows participants in these extracurricular activities to reflect on their own language and their own culture. Based on the postulates of this important Brazilian educator, it is possible to say that these workshops are considered, somehow, a measure of social justice, because they are public and free and have as main purpose the deelitization of the teaching-learning of additional languages.

KEYWORDS: Youth and Adult Education; Public school; Italian as an additional language; Haitian Creole as an additional language.

ABSTRACT: L'obiettivo di questo articolo è quello di presentare il Centro Integrato di Educazione di Giovani e Adulti (CIEJA) Perus I - una scuola pubblica municipale che si trova nella città di San Paolo (SP) - e due attività extracurricolari svolte in questa scuola: i laboratori di italiano e di creolo haitiano. Per raggiungere questo scopo, all'inizio abbiamo descritto questa istituzione, le cui pratiche di insegnamento sono fortemente basate sulle idee di Paulo Freire (1974), un autore per cui l'educazione è un diritto che va garantito a tutti. Poi abbiamo trattato il funzionamento di queste attività extracurricolari e ci siamo concentrate sui laboratori di italiano e creolo haitiano come lingue aggiuntive. Questi laboratori sono spazi pubblici e collettivi di costruzione collaborativa di conoscenze e riflessioni critiche su queste lingue e le loro culture. Ciò permette a quelli che partecipano a tali attività extracurricolari di riflettere anche sulle loro lingue e le loro culture. In base alle idee di questo importante autore brasiliano, si può dire che questi laboratori siano comunque una misura di giustizia sociale perché sono pubblici e gratuiti e il loro principale scopo è quello di promuovere la deelitizzazione dell'insegnamento-apprendimento delle lingue aggiuntive.

PAROLE CHIAVE: Educazione di Giovani e Adulti; Scuola pubblica; Italiano come lingua aggiuntiva; Creolo haitiano come lingua aggiuntiva. 


\section{Introdução}

O presente artigo consiste em uma versão expandida da comunicação que apresentamos em outubro de 2020 no VI Encontro Internacional de Italianistas e Professores de Italiano do Brasil, evento realizado virtualmente. Neste texto, temos como objetivo apresentar o Centro Integrado de Educação de Jovens e Adultos (CIEJA) Perus I - instituição educacional da rede pública municipal de São Paulo - e duas atividades extracurriculares desenvolvidas nessa escola: as oficinas de italiano e de crioulo haitiano.

Para atingir tal objetivo, organizamos o artigo em três seções. A seção 1 consiste nesta introdução; as duas seções subsequentes pautam-se, sobretudo, nos postulados de Paulo Freire (1974), autor de importância fundamental para a Educação em geral e, especialmente, para a Educação de Jovens e Adultos (EJA). Na seção 2, discorreremos sobre o Centro Integrado de Educação de Jovens e Adultos (CIEJA), que é uma das modalidades da EJA do município de São Paulo. Por sua vez, na seção 3, trataremos das oficinas de italiano e de crioulo haitiano, que são oferecidas no CIEJA Perus I (instituição onde lecionamos) aos estudantes dessa escola e a interessados em geral, visando garantir o acesso de todos ao ensino-aprendizagem dessas duas línguas adicionais.

Por fim, apresentaremos nossas considerações finais, que buscam sintetizar as ideias e reflexões apresentadas neste artigo, bem como fazer uma denúncia contra o descaso do governo em relação à escola pública, que, desde o início da pandemia causada pelo coronavírus, vem sendo cada vez mais marginalizada e negligenciada.

\section{O CIEJA e a educação como direito de todos}

A EJA é um direito humano fundamental, postulado pela perspectiva da educação ao longo da vida. Segundo o artigo 37 da LDB 9394/96, a EJA destina-se "àqueles que não tiveram acesso ou continuidade de estudos no ensino fundamental e médio na idade própria”. Assim, essa modalidade da educação básica tem como público-alvo jovens, adultos e idosos que, por diversos motivos, não puderam frequentar a escola na idade considerada a mais apropriada. Sem dúvida, tais motivos estão diretamente relacionados à grande desigualdade social existente no Brasil, a qual dificulta ou, até mesmo, impede o acesso de muitas pessoas às escolas e/ou a sua permanência nas instituições educacionais.

Na rede pública municipal de ensino de São Paulo, há 5 (cinco) tipos ${ }^{1}$ de EJA, a saber:

1. a EJA regular, que é oferecida no período noturno em escolas públicas municipais de ensino fundamental e/ou de ensino fundamental e médio, nas quais, em quatro etapas, os discentes podem concluir o ensino fundamental. Cada etapa dura um ano e abrange 200 (duzentos) dias letivos;

1 Informações retiradas do documento intitulado Currículo da Cidade: Educação de Jovens e Adultos (SÃO PAULO, 2019). 
2. o Movimento de Alfabetização (MOVA-SP), que se trata de uma parceria entre a Secretaria Municipal de Educação de São Paulo (SME-SP) e Organizações da Sociedade Civil para combater o analfabetismo, organizando classes de alfabetização de jovens e adultos;

3. o Centro Integrado de Educação de Jovens e Adultos (CIEJA), unidade educacional que atende jovens e adultos em três períodos (manhã, tarde e noite), em até seis turnos diários, e que lhes possibilita concluir o ensino fundamental em quatro anos, oferecendo-lhes, também, atividades extracurriculares. Por isso, podemos afirmar que os CIEJAs são escolas configuradas, exclusivamente, para o público da EJA, inclusive, no que concerne à distribuição de tempos e espaços, o que faz dessa modalidade uma alternativa para quem precisa frequentar a escola em outros horários, além do período noturno. A cidade de São Paulo possui 16 (dezesseis) CIEJAs; o CIEJA Perus I é o mais novo desse município;

4. O Centro Municipal de Capacitação e Treinamento (CMCT), que oferece cursos de formação profissional de curta duração. A cidade apresenta somente 2 (dois) CMCTs, e ambos estão localizados na zona leste;

5. A EJA modular, que é oferecida apenas no período noturno em escolas municipais de ensino fundamental e é dividida em quatro módulos, cada qual com a duração de 50 (cinquenta) dias letivos.

Neste artigo, nos concentraremos no CIEJA, pois as atividades extracurriculares sobre as quais discorreremos foram realizadas no CIEJA Perus I durante o ano letivo de 2019 e o início do ano letivo de 2020 (tivemos aulas presenciais até meados de março de 2020; depois disso, devido à pandemia, por determinação legal, todas as escolas foram fechadas).

Em tal CIEJA, assim como em tantas instituições que se dedicam à EJA, há a preocupação de atender as especificidades e as necessidades educacionais, culturais e sociais dos jovens, adultos e idosos que o frequentam. Para tanto, nós, docentes, juntamente com a equipe gestora e com os demais funcionários dessa escola, procuramos promover o respeito e a valorização da diversidade geracional, social, étnico-racial, cultural, de gênero e de ritmos de aprendizagem.

O CIEJA Perus I entrou em funcionamento em 2016 e, atualmente, atende cerca de 1300 (mil e trezentos) discentes brasileiros e migrantes internacionais, cuja faixa etária varia entre 15 e 80 anos. Por se tratar de uma unidade escolar de inspiração freiriana, o CIEJA é, fundamentalmente, um local de formação, cujo escopo consiste na construção de conhecimentos de maneira crítica, dialógica, colaborativa e reflexiva (FIALHO; VIEIRA; FERREIRA, 2020).

Dentre esses estudantes, há, como já mencionado, jovens, adultos e idosos que, por variados motivos, não tiveram a oportunidade de iniciar ou concluir seus estudos na chamada "idade certa"; há, outrossim, adolescentes que não se adaptaram à escola regular, sendo, por conseguinte, rotulados como "alunos-problema" (alguns dos quais são egressos do sistema prisional); migrantes, principalmente haitianos, que, por serem negros, sofrem racismo e xenofobia; e pessoas com deficiência, que também são vítimas de preconceitos. Em suma, temos um corpo discente constituído por aqueles que são invisibilizados e marginalizados no Brasil. 
Uma característica muito marcante dessa instituição educacional é a grande quantidade de alunos haitianos: no total, são cerca de 700 (setecentos) educandos oriundos de diversas cidades do Haiti. Ademais, há, nesse CIEJA, uma estudante boliviana e um angolano. Desse modo, tendo em vista que mais da metade do corpo discente é constituída por migrantes internacionais, podemos dizer que, em tal escola, circulam diferentes línguas. Por essa razão, também procuramos visibilizar e valorizar essa diversidade linguística e cultural, que é tão presente em tal instituição. Sobre essa diversidade, discorreremos mais adiante; agora, abordaremos o funcionamento da unidade educacional em questão.

O CIEJA Perus I fica aberto de segunda a sexta-feira das $7 \mathrm{~h} 30$ às $22 \mathrm{~h} 15$, oferecendo aulas em três turnos diários (matutino, vespertino e noturno). Cada turno divide-se em dois períodos, totalizando, assim, seis períodos de aulas. Apesar de cada educando estar matriculado em um período, se, por qualquer motivo, o estudante não puder comparecer à escola no horário em que ele está matriculado, ele pode frequentar aulas em outros períodos. Desse modo, os discentes podem comparecer à escola em diversos horários, que vão desde às $7 \mathrm{~h} 30$ da manhã (horário de início das aulas do primeiro período) até às $20 \mathrm{~h}$ (horário em que se iniciam as aulas do sexto e último período). Essa configuração possibilita regularidade na frequência escolar dos trabalhadores-estudantes, uma vez que eles, muitas vezes, mudam de horário em seus trabalhos (ARROYO, 2017).

No CIEJA, os alunos têm aulas regulares (isto é, das disciplinas que fazem parte do currículo) de segunda a quinta-feira, e cada aula tem a duração de duas horas e quinze minutos. Nesses quatro dias, os estudantes do ensino fundamental I têm aulas de alfabetização, ministradas por professoras polivalentes e que, portanto, trabalham todas as disciplinas curriculares nessas aulas. Por sua vez, os discentes do ensino fundamental II têm aulas com diversos professores e cada um desses docentes ministra uma disciplina que faz parte do currículo, o qual é organizado nas seguintes áreas: linguagens e códigos (língua portuguesa, língua inglesa, arte e educação física); ciências naturais e matemática; ciências humanas (história e geografia).

Já às sextas-feiras, são oferecidas oficinas, que consistem em atividades extracurriculares, as quais são abertas não apenas aos educandos, mas também à comunidade externa. Por esse motivo, é comum que pessoas que não estejam matriculadas no CIEJA participem das oficinas, sobretudo parentes e amigos dos estudantes e dos funcionários dessa escola (VIEIRA, 2019). Alguns exemplos de oficinas já oferecidas aos alunos e à comunidade externa são: ioga, música, jogos matemáticos, maquiagem, informática, italiano, crioulo haitiano, entre outras. Nossas últimas oficinas foram ministradas em março de 2020; tiveram de ser suspensas devido à pandemia de COVID-19. Assim que passar a pandemia, esperamos poder retomar essas atividades extracurriculares. Na próxima seção, discorreremos sobre duas delas: as oficinas de italiano e de crioulo haitiano. 


\section{As oficinas de italiano e crioulo haitiano no CIEJA Perus I: pelo direito de todos à aprendizagem de línguas adicionais}

Na EJA, a única língua adicional (LA) que faz parte do currículo é o inglês. Embora saibamos que, nos documentos oficiais da rede pública municipal de São Paulo, inclusive no Currículo da Cidade (SÃO PAULO, 2019), seja utilizado o termo língua estrangeira (LE) para se referir ao inglês, escolhemos utilizar o termo língua adicional, em vez de língua estrangeira. Fizemos tal opção porque esse último termo, segundo Leffa e Irala (2014), Schlatter e Garcez (2012), entre outros autores, baseia-se apenas em um critério geográfico, isto é, considera-se língua estrangeira a língua aprendida em um espaço onde ela não tem o status de língua oficial. Essa definição, consequentemente, não leva em consideração o próprio aprendiz; leva em conta apenas esse critério geográfico.

Já a definição de língua adicional é centrada no sujeito que aprende a língua. O termo LA, de acordo com Leffa e Irala (2014), diz respeito à língua que o discente aprende por acréscimo e que tem, por conseguinte, como ponto de partida, outras línguas que o aluno já conhece. Os dois autores asseveram que, como o ensino da LA parte da primeira língua do aprendiz, há uma tendência "de se valorizar o contexto do aluno, desde suas práticas sociais, os valores de sua comunidade e uma visão crítica da aprendizagem da língua” (LEFFA; IRALA, 2014, p. 22).

Com base nesses postulados, pode-se afirmar que o termo língua adicional se refira a fatores internos ao sujeito, ou melhor, à(s) língua(s) que ele já conhece, e não a critérios geográficos (como é o caso do termo língua estrangeira) ou à sequência de aprendizagem das línguas (como é o caso do termo segunda língua - L2).

Ademais, a definição de língua adicional demonstra uma concepção heteroglóssica de língua (BAKHTIN, 1981), isto é, uma visão conforme a qual as línguas aprendidas pelo sujeito não estão separadas dentro dele; elas se entrelaçam, dialogam entre si e são interdependentes. Já o emprego dos termos LE e L2 parece remeter a uma visão monoglóssica de língua, visto que se baseia na ideia de que há uma compartimentação de línguas no sujeito, considerando-as como códigos separados. Por concordarmos com tais postulados, optamos por usar, neste artigo, o termo LA, apesar de termos ciência de que, na área de ensino-aprendizagem de italiano, são utilizados, quase exclusivamente, os termos língua estrangeira e segunda língua.

É provável que a exclusividade do inglês como LA na EJA se deva ao fato de tratar-se de uma língua de comunicação internacional, considerada, assim, uma língua hegemônica. Aliás, Schlatter e Garcez (2012) salientam que o inglês é uma língua adicional valorizada, o que sugere a compreensão de que há, também, línguas adicionais não valorizadas. Essa compreensão parece, de certa forma, corroborar a hegemonia do inglês, em detrimento de outras línguas. Apesar de refutarmos concepções que hierarquizam as línguas, atribuindo maior valor a algumas e marginalizando outras, não podemos negar a importância de conhecer uma língua hegemônica, uma vez que vivemos em um mundo globalizado, em que o inglês ocupa uma posição de destaque. Isso já justifica a relevância de se estudar a língua inglesa em todas as modalidades de ensino, inclusive na EJA. 
No entanto, consideramos que o inglês não deva ser a única língua adicional oferecida a nossos educandos da EJA, pois à medida que os alunos conhecem outras línguas, eles ampliam as suas possibilidades de significar, de interagir e de circular em diferentes contextos sócio-histórico-culturais (LIBERALI et al., 2017). Assim, quanto maior for o número de línguas a que os discentes têm acesso, mais numerosos serão os contextos de que eles poderão participar.

Como as oficinas são gratuitas e abertas não só aos estudantes matriculados nessa instituição educacional, mas também à comunidade externa, as oficinas de italiano e crioulo haitiano consistem em espaços públicos e coletivos de construção colaborativa de conhecimentos e reflexões críticas sobre essas línguas e suas respectivas culturas, o que permite aos participantes das oficinas refletir, também, sobre a sua própria língua e a sua própria cultura. Visto que há diversas definições de língua e cultura, julgamos pertinente explicitar as definições em que nos pautamos e salientar que, a nosso ver, língua e cultura são indissociáveis.

Com base em Bakhtin e Volochinov (1986, p. 95), podemos afirmar que a língua constitui o sujeito e consiste em um fenômeno social que "se realiza através da interação verbal social dos locutores". Já a cultura, por sua vez, é entendida como uma

complexa teia de significados, os quais inscrevem-se e são inscritos no fluxo permanente da ação social, ou seja, ela não pode ser considerada como algo que existe de per si, como um fenômeno que exerce as suas "forças" independentemente do acontecimento (GEERTZ, 1978 apud MENDES, 2015, p. 213)

Assim, admitimos que o ensino da língua (no caso das nossas oficinas, o italiano e o crioulo haitiano) visa propiciar aos educandos a possibilidade de compreenderem e vivenciarem "outra cultura, cuja língua é a sua dimensão primeira" (MENDES, 2015, p. 213). Essa compreensão e essa vivência não significam, contudo, que os estudantes devam abandonar a sua própria língua e a sua própria cultura; significa que, ao conhecerem outra língua e sua respectiva cultura, os alunos experienciam trocas culturais, que lhes possibilitam ampliar o próprio repertório. Tal ampliação envolve um diálogo entre línguas e culturas, e não o apagamento de uma delas ou a hierarquização entre elas. Nessa perspectiva, não há uma anulação de si, nem do outro; há, sim, um intercâmbio linguístico-cultural, que contribui para o desenvolvimento de reflexões críticas sobre si e sobre o outro.

Tendo em vista a necessidade e a relevância de uma construção colaborativa de saberes e dessas reflexões críticas, possibilitadas pelo trabalho com línguas adicionais, decidimos propor as oficinas de italiano e crioulo haitiano. Tomamos essa decisão também para, de certo modo, contribuir com a desconstrução da hegemonia do inglês na rede pública municipal de ensino, pois, como já procuramos explicar, rechaçamos as perspectivas que colocam uma língua em posição superior às outras. Com essa proposta, visamos visibilizar e valorizar diferentes línguas, bem como propiciar o acesso de todos os educandos e da comunidade externa à aprendizagem de línguas adicionais. Isso porque, no Brasil, como sabemos, geralmente, somente têm 
esse acesso aqueles cujas condições financeiras lhes permitem pagar por aulas de LA particulares ou ministradas em escolas e institutos privados.

Ambas as oficinas foram planejadas e implementadas por nós (Daniela e Cristiane, professoras do CIEJA Perus I) de abril de 2019 até março de 2020. Pretendemos retomá-las quando passar a pandemia, como já mencionamos. Convém salientar que, devido à frequência irregular dos estudantes (o que é muito comum na EJA, sobretudo porque muitos alunos são, antes de tudo, trabalhadores), tanto nas aulas quanto nas oficinas, não propúnhamos atividades extensas, que teriam continuidade na aula posterior; todas as atividades realizadas em nossas oficinas começavam e terminavam no mesmo dia. Isso permitia que qualquer estudante pudesse participar delas, mesmo que não tivesse participado das oficinas anteriores.

As oficinas de italiano eram ministradas pela primeira autora deste artigo (Daniela) e contavam, inicialmente, com a colaboração de um dos professores de português, e, posteriormente, com a colaboração da segunda autora (Cristiane).

Já as oficinas de crioulo haitiano eram, no início, planejadas e ministradas pelo estudante haitiano Olson Oscar sob a orientação da segunda autora. Posteriormente, passaram a ser planejadas e ministradas não só por Olson, mas também por Donald Maignan, que também é haitiano e aluno do CIEJA. Tanto o planejamento quanto a execução das aulas passaram a ser supervisionadas por nós duas, visto que nossos dois estudantes-professores são falantes de crioulo haitiano, porém não têm formação pedagógica. Vale ressaltar que ambos trabalharam voluntariamente como professores de crioulo, compartilhando seus saberes com os discentes do CIEJA, com a comunidade externa e conosco. A seguir, exporemos algumas reflexões concernentes às oficinas de italiano. Posteriormente, apresentaremos algumas reflexões que dizem respeito às oficinas de crioulo haitiano.

No que tange às oficinas de italiano, levando em conta que o Brasil é um dos países que mais recebeu italianos, essa é a língua materna dos ancestrais de muitos brasileiros. A língua e a cultura italianas estão fortemente presentes no nosso dia a dia, tanto para aqueles que são descendentes de italianos quanto para os que não o são. É o que se percebe, por exemplo, pela presença de pratos italianos muito apreciados em nosso país (tais como: pizza, gnocchi, spaghetti etc.) e, até mesmo, quando, em diversas situações cotidianas, nos despedimos de alguém dizendo-lhe "tchau", palavra que se originou do cumprimento italiano "ciao".

Em conversas informais com alunos brasileiros do CIEJA, descobrimos que alguns deles têm ascendência italiana e que muitos, embora não tenham vínculos familiares com a Itália, têm interesse e curiosidade em conhecer a língua italiana. Destarte, as oficinas de italiano consistem em uma ótima oportunidade para que os alunos do CIEJA e a comunidade externa tenham acesso à quarta língua mais estudada do mundo (MAUGERI, 2016), uma língua de grande importância em diversas áreas, tais como: as Artes, o Direito, a Música, as Letras, a Filosofia etc.

Temos a esperança de que, um dia, possamos viver em um país com justiça social (ou, no mínimo, com menos injustiça), onde nossos educandos da EJA - brasileiros e migrantes possam estudar essas áreas e/ou quaisquer outras que eles desejarem. Aqui, usamos a palavra 
"esperança" na acepção freiriana: "Não é, porém, a esperança um cruzar de braços e esperar. Movo-me na esperança enquanto luto e, se luto com esperança, espero" (FREIRE, 1974, p. 53).

Quanto aos estudantes de outras nacionalidades (haitianos, em sua maioria), também em conversas informais, descobrimos que muitos deles falam, além do crioulo haitiano (sua primeira língua), o francês (que, no Haiti, é a língua da escolarização), o espanhol e o inglês; ou seja, nenhum deles tinha tido contato com a língua italiana antes de ingressar no CIEJA. Desse modo, as oficinas de italiano foram muito bem-recebidas por tais educandos, que viram, nessas atividades extracurriculares, a oportunidade de conhecer uma língua que eles nunca tinham estudado.

Assim, ao propor oficinas de italiano na EJA, modalidade educacional tão negligenciada pelo poder público, pretendemos oferecer o acesso a essa LA a quem está às margens, a quem é invisibilizado neste país repleto de injustiça social: adolescentes considerados "alunos-problema" (alguns dos quais já passaram pelo sistema prisional); jovens, adultos e idosos a quem foi roubado o direito de estudar na "idade certa"; migrantes internacionais que vieram ao Brasil em busca de melhores condições de vida; pessoas com deficiência. Essa proposta é, a nosso ver, uma forma de lutar por um país menos desigual, um país onde aprender outras línguas se torne, de fato, um direito de todas as pessoas, e não um privilégio de algumas.

No que concerne às oficinas de crioulo haitiano, no CIEJA Perus I, há um grande número de alunos haitianos, o que justifica a relevância da aprendizagem dessa língua pela comunidade escolar (professores, estudantes, funcionários) e pela comunidade externa (pessoas que vivem em Perus, distrito onde residem muitos de nossos discentes haitianos e onde se localiza a nossa escola).

O CIEJA Perus I foi inaugurado em 2016, e a comunidade haitiana já estava naquele território, no entanto, os haitianos não conseguiam acesso a escolas públicas da região; esses discentes encontraram acolhimento no CIEJA, e percebemos que o maior interesse deles era, inicialmente, aprender a língua portuguesa, para, assim, conseguir se inserir mais facilmente na sociedade brasileira.

Em 2017, percebemos que seria importante termos uma oficina de crioulo haitiano, não só para que os estudantes brasileiros pudessem aprender uma língua adicional, mas também para que o crioulo haitiano pudesse circular nos ambientes sociais de Perus, distrito habitado tanto por brasileiros quanto por haitianos, o que poderia aumentar a proximidade e promover maior interação entre eles.

Naquele ano, tínhamos estudantes haitianos dispostos a serem professores voluntários nas oficinas de crioulo, mas não havia docentes suficientes que pudessem acompanhar e dar suporte pedagógico a eles. É importante salientar que, em 2017, havia uma necessidade maior de aproximação entre alunos brasileiros e haitianos, visto que eram perceptíveis comportamentos xenofóbicos, que interferiam nos relacionamentos.

Para enfrentar esses comportamentos, organizou-se uma festa da cultura haitiana, que, inclusive, recebeu do instituto Tomie Ohtake², em 2017, o prêmio Territórios. Nessa festa, houve uma

2 O Instituto Tomie Ohtake, localizado no bairro de Pinheiros (São Paulo-SP), é um espaço projetado arquite- 
apresentação desses migrantes para os discentes brasileiros e para a comunidade em geral e, a partir desse evento, começou a existir, então, um interesse em se conhecer mais a cultura haitiana, principalmente a culinária e a língua. Portanto, a ideia de organizar as oficinas de crioulo haitiano partiu, primeiramente, de discentes brasileiros em consonância com os estudantes haitianos.

Como acreditamos na valorização (e não na hierarquização) das línguas e sabemos da importância da aprendizagem de línguas adicionais, era nosso desejo termos, concomitantemente, outras oficinas de línguas adicionais, mas, como já mencionado, não havia professores em número suficiente na época.

Em 2019, finalmente, tornou-se possível propor as oficinas de crioulo, que, como explicamos, são ministradas pelos alunos-professores Olson Oscar e Donald Maignan. Essas atividades extracurriculares consistem em uma ótima oportunidade de conhecer a primeira língua de muitos moradores de Perus: os haitianos que deixaram o seu país em busca de condições de vida com dignidade. Nessa direção, tais oficinas são muito importantes, porque permitem uma maior integração entre brasileiros e haitianos. Além disso, são raros os locais onde existe a possibilidade de estudar essa língua. Portanto, essas oficinas realmente constituem um ensejo para a aprendizagem do crioulo haitiano.

As oficinas de italiano e de crioulo haitiano aconteciam às sextas-feiras no período noturno no CIEJA: a primeira era das $18 \mathrm{~h}$ às $19 \mathrm{~h} 30$, e a segunda, das $20 \mathrm{~h} 15$ às $21 \mathrm{~h} 45$. Optamos por não oferecer as duas oficinas no mesmo horário para que os discentes e os interessados em geral pudessem participar de ambas caso desejassem. Desde os primeiros encontros, tivemos uma boa adesão dos aprendizes e da comunidade externa. De ambas as oficinas, participavam os estudantes dessa instituição educacional, bem como alguns funcionários e professores, além de pessoas da comunidade externa, as quais moram no entorno da escola.

Recentemente, funcionários da Unidade Básica de Saúde (UBS) localizada em Perus nos procuraram com interesse em oficinas de crioulo haitiano voltadas ao vocabulário da área de saúde, visto que, cada vez mais, tem aumentado o número de mulheres haitianas sendo atendidas nessa UBS. Após esse momento pandêmico, temos a intenção de ampliar as oficinas de crioulo haitiano, oferecendo aulas com vocabulário específico para os funcionários da área da saúde.

Com essas oficinas de línguas adicionais, temos o propósito de garantir a todos os partícipes (educandos, professores, funcionários e comunidade externa) o direito de aprender outras línguas, pois, quando uma pessoa aprende uma LA, além de conhecer uma nova língua e uma

tônica e conceitualmente para realizar mostras nacionais e internacionais de artes plásticas, arquitetura e design. Além de um programa de exposições que se desdobra em outras atividades como debates, pesquisa, produção de conteúdo, documentação e edição de publicações, o Instituto Tomie Ohtake desenvolve, desde a sua fundação, ampla pesquisa no ensino da arte contemporânea. Por isso, foi pioneiro na criação de novos processos para a formação de professores e de alunos das redes pública e privada, além de realizar uma série de atividades dirigidas ao público em geral e projetos de estímulo ao desenvolvimento da produção contemporânea. O Prêmio Territórios, iniciativa desse instituto, busca mapear, reconhecer e dar visibilidade a projetos que fortaleçam o vínculo entre as escolas e os territórios a partir dos diversos saberes culturais, compreendendo a cidade como espaço de aprendizagem. Essas informações estão disponíveis em: https://www.institutotomieohtake.org.br/o_instituto/sobre. Acesso em: 15 jun. 2021. 
nova cultura, ela pode refletir criticamente sobre a sua própria língua e a sua própria cultura, utilizando, para tanto, todo o seu repertório.

Segundo Busch $(2012,2015)$, a noção de repertório está relacionada à trajetória de vida do sujeito, a qual se constrói de acordo com o contexto social, histórico, político e cultural de que ele faz parte. Visto que o repertório possui essa dimensão biográfica, ele é constituído por todos os recursos verbais (as línguas que o sujeito conhece) e não verbais (gestos, expressões faciais, uso de objetos presentes no espaço etc.) de que o sujeito dispõe para interagir no mundo, para construir sentidos.

De acordo com Blommaert e Backus (2013), como o repertório reflete a vida do sujeito e, portanto, todas as experiências vivenciadas por ele, o repertório remete não apenas ao seu local de nascimento, mas também a todos os espaços socioculturais, históricos e políticos onde o sujeito vive(u). $\mathrm{O}$ fato de o repertório remeter a todas as experiências vivenciadas pelo sujeito em diversos espaços é de fundamental relevância na EJA. Isso porque os estudantes dessa modalidade educacional, por serem adolescentes, jovens, adultos e idosos, têm variadas trajetórias humanas, sociais, cognitivas, culturais e linguísticas que precisam ser consideradas tanto nas aulas (disciplinas curriculares) quanto nas atividades extracurriculares.

Por essa razão, as oficinas de italiano e crioulo buscam levar em conta essas trajetórias biográficas e ampliar o repertório de seus participantes. Assim, tais atividades extracurriculares consistem em uma oportunidade singular para que sejam oferecidas a cada um dos participantes condições de desenvolver, conscientemente, reflexões críticas sobre si mesmo e sobre o outro.

Nesse sentido, a aprendizagem de uma LA pode ser compreendida como um processo em que se estabelecem laços, vínculos entre a nossa própria língua/cultura e outras línguas/culturas, um processo em que se constroem pontes entre a nossa própria cultura e a cultura do outro, pontes que nos permitem diminuir as fronteiras, as distâncias entre nós e o outro. É dessa forma que a língua adicional passa a ser nossa também, pois vamos, aos poucos, nos apropriando dela e, então, ela vai passando a fazer parte do nosso repertório e vai nos constituindo como sujeitos bi/multilíngues.

Para Paulo Freire (1974), os educandos jovens e adultos, ao se apropriarem da leitura e da escrita em sua própria língua, aprendem a dizer a sua palavra. Acerca da importância de se apropriar da palavra e da necessidade de que essa apropriação seja um direito, Freire (1974, p. 50 , itálicos nossos) nos explica que

não é no silêncio que os homens se fazem, mas na palavra, no trabalho, na ação-reflexão. Mas, se dizer a palavra verdadeira, que é trabalho, que é práxis, é transformar o mundo, dizer a palavra não é privilégio de alguns homens, mas direito de todos os homens.

Assim, com base nessa ideia do grande educador brasileiro, a nosso ver, ao terem acesso a uma língua adicional, esses mesmos educandos podem aprender a dizer a sua palavra e, também, a palavra do outro. Por conseguinte, nesse processo crítico-colaborativo de aprendizagem, o diálogo se estabelece de tal forma que os educandos não só têm a oportunidade de refletir sobre a sua própria língua e a sua própria cultura, como também sobre a língua adicional e a sua respectiva cultura, que também passam a ser, de certo modo, deles. 
Como dissemos, em geral, os cursos de línguas adicionais são, em sua maioria, destinados apenas àqueles cujo poder aquisitivo permite pagar pelas aulas. No caso do italiano, por exemplo, os cursos oferecidos na cidade de São Paulo (em instituições como o Circolo Italiano, o Instituto Italiano de Cultura e o Instituto Cultural Ítalo-brasileiro) custam cerca de $\mathrm{R} \$ 1500,00$ (mil e quinhentos reais) por semestre; esse é o valor médio de um curso de 40-45 horas e não inclui o valor do material didático. Diante desses preços, a maioria dos educandos do CIEJA e da comunidade do entorno (moradores de Perus e arredores) não poderia ter acesso ao italiano.

Nesse sentido, reiteramos que as oficinas de italiano e de crioulo do CIEJA podem ser consideradas, de certo modo, como uma medida de justiça social (FREIRE, 1974), já que as nossas oficinas são públicas e gratuitas, o que possibilita a participação de todos, inclusive daqueles que, infelizmente, vivem em situação de alta vulnerabilidade social.

Dessa maneira, as oficinas de línguas adicionais do CIEJA parecem materializar, em larga medida, os postulados de Paulo Freire (1974), porquanto buscam garantir oportunidades de aprendizagem do italiano e do crioulo haitiano para todos, o que pode ser visto como uma tentativa de deselitização do ensino-aprendizagem de línguas adicionais. Nas próximas seções, para ilustrar um pouco do trabalho didático-pedagógico realizado em ambas as oficinas, comentaremos algumas atividades realizadas nas oficinas de italiano e, posteriormente, comentaremos o planejamento inicial das oficinas de crioulo haitiano.

\subsection{Algumas atividades realizadas nas oficinas de italiano}

No CIEJA, o ensino é temático, ou seja, organiza-se com base em temas escolhidos pelos estudantes, temas que dialogam com a realidade em que eles vivem. Nas aulas que acontecem de segunda a quinta-feira (disciplinas que fazem parte do currículo da escola), cada tema é estudado sob diferentes perspectivas, uma vez que é trabalhado em todas as disciplinas. Esse estudo equivale a uma rodada, cuja duração é, geralmente, de 27 a 30 dias letivos, mas, em decorrência da amplitude e da complexidade de determinados temas, uma rodada pode se estender, inclusive, a um semestre. Por isso, no planejamento de algumas das nossas oficinas de italiano, procuramos levar em conta essas rodadas temáticas.

Quando realizamos as primeiras oficinas, por exemplo, o tema da rodada vigente era "mulheres na sociedade atual". Dentro dessa temática, nas diferentes disciplinas, foram desenvolvidas atividades didáticas que problematizavam o machismo, a misoginia, a maternidade compulsória etc., com o propósito de fazer com que os estudantes refletissem criticamente sobre a temática em questão. Visando alcançar essa finalidade, em uma das oficinas de italiano, fizemos as seguintes atividades:

1. Discussão com base nestas perguntas: "Avete mai sentito parlare del micro-maschilismo? Cosa ne sapete?". A discussão, cujo objetivo principal consistia em propor reflexões iniciais sobre o machismo presente na vida cotidiana de todos nós, foi feita em italiano, em português e em crioulo haitiano, pois, na oficina realizada naquele dia, havia, 7 (sete) discentes brasileiros, e 10 (dez) haitianos. 
2. Após a discussão, fizemos a leitura compartilhada do texto "Micro-maschilismo: 15 frasi comuni che perpetuano la disuguaglianza di genere"': lemos, juntos, esse texto e, durante a leitura, fizemos pausas para conversar sobre cada trecho lido e para esclarecer dúvidas lexicais.

3. Concluída essa leitura compartilhada, os estudantes se organizaram em pequenos grupos para fazer a seguinte atividade: associar as 15 (quinze) frases machistas presentes no texto à sua respectiva tradução em português. Foi entregue a cada grupo um envelope contendo essas frases em italiano e sua respectiva tradução ${ }^{4}$. Essa atividade teve como escopo central o desenvolvimento da compreensão escrita em italiano e em português, uma vez que alguns dos educandos que participaram da oficina naquele dia não têm o português como primeira língua; ademais, alguns estudantes brasileiros presentes naquele encontro ainda estavam em processo de alfabetização. A figura 1 ilustra tal atividade:

Figura 1 - Frases que demonstram micromachismo

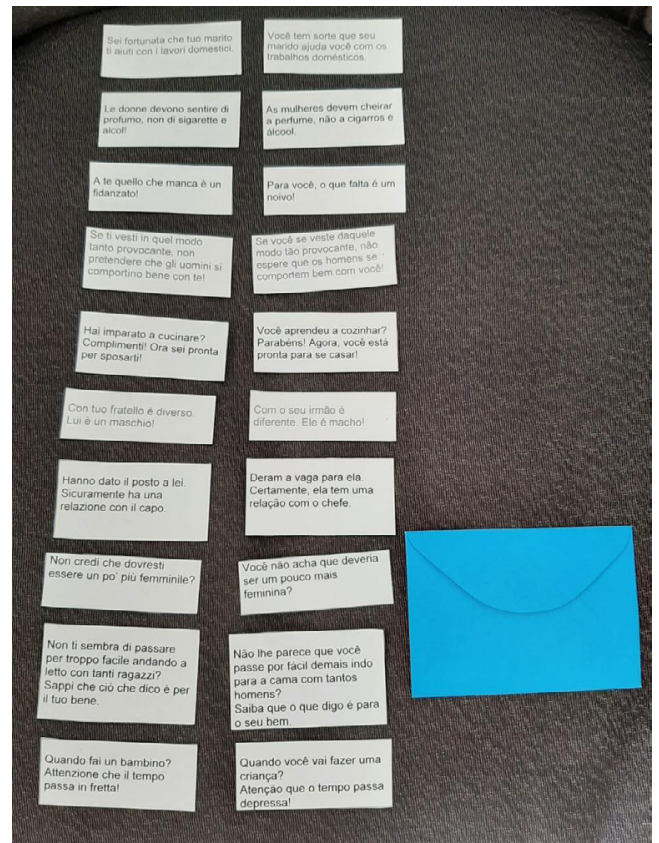

Fonte: fotografia tirada por uma das autoras deste artigo.

3 Disponível em: https://curiosandosimpara.com/2018/03/10/micro-maschilismo-15-frasi-comuni-perpetuano-la-disuguaglianza-genere/. Acesso em: 30 abr. 2019.

4 As frases foram retiradas do texto "Micro-maschilismo: 15 frasi comuni che perpetuano la disuguaglianza di genere" e traduzidas para o português pela primeira autora, que é ministrante das oficinas de italiano do CIEJA Perus I. 
1. Quando todos os grupos finalizaram essa atividade, mostramos-lhes slides com as frases em italiano e as frases correspondentes a elas em português, para que os discentes pudessem conferi-las.

2. Para finalizar, propusemos uma discussão sobre estas questões: a) "Ragazze, avete già sentito da qualche amico, parente o addirittura da un'amica qualche frase come quelle? Come avete reagito?"; b) "Ragazzi, avete già detto qualche frase come quelle ad una donna? Se sì, chi era (un'amica, la mamma, la fidanzata, la moglie ecc.)? Perché gliel'avete detto?"; c) "Secondo voi, cosa possiamo fare per combattere le frasi e gli atteggiamenti (micro) maschilisti?". Nessa discussão, os educandos tiveram a possibilidade de expressar suas ideias e opiniões tanto em italiano quanto em português e em crioulo haitiano, o que contribuiu para que todos participassem da atividade e refletissem sobre suas experiências pessoais relacionadas ao micromachismo.

Em todas as atividades desenvolvidas no referido encontro, procuramos não só trabalhar a compreensão escrita em língua italiana e em língua portuguesa e a produção oral em ambas as línguas, mas também contribuir para que os partícipes refletissem criticamente sobre o machismo presente em nosso dia a dia e percebessem que essa presença se revela tanto na cultura brasileira quanto nas culturas italiana e haitiana (algumas alunas haitianas nos relataram que, em seu país, frases repletas de micromachismo, como as que vimos na aula, também são comuns). Acreditamos, com base em Freire (1974), que, com essas atividades, enquanto aprendem línguas adicionais (o italiano, no caso dos estudantes brasileiros; e o italiano e o português, no caso dos alunos haitianos), os educandos podem, outrossim, refletir criticamente sobre essa realidade cotidiana, deixando de naturalizá-la e buscando formas de transformá-la.

\subsection{Algumas atividades realizadas nas oficinas de crioulo haitiano}

Sabemos que, no Brasil, geralmente, existe a ideia de que há muita receptividade em relação aos migrantes, por isso, é considerado um país que acolhe todos. No entanto, em se tratando de migrantes oriundos de países empobrecidos, essa receptividade não é a mesma, o que fica mais evidente quando o migrante é negro e falante de uma língua que não é considerada de prestígio, como é o caso do crioulo haitiano.

É notório que o Brasil é um país estruturalmente racista (ALMEIDA, 2019), herança da colonização e do deslocamento forçado das pessoas que foram escravizadas, por conseguinte, nossas diversas instituições também são racistas. Por esse motivo, os migrantes negros não costumam ser bem-recebidos e, desse modo, não têm seus direitos garantidos, são vítimas da discriminação racial e da xenofobia.

Com o escopo de enfrentar essa conjuntura estrutural, que é racializada, nós, do CIEJA Perus I, trabalhamos numa perspectiva que busca garantir direitos a esses migrantes que são marginalizados, excluídos e explorados. Para tanto, procuramos visibilizar e valorizar suas línguas e suas respectivas culturas, que, como já dissemos, são indissociáveis.

Desse modo, as oficinas de crioulo haitiano representaram, desde o início, um desejo de 
garantia de acesso a outras línguas e às demandas dos estudantes, tanto brasileiros quanto haitianos, já que o acesso ao crioulo haitiano, por parte dos brasileiros, poderia facilitar a comunicação, não só no espaço escolar, mas também no território do distrito de Perus. Como nós, professoras, não falamos crioulo haitiano, era necessária, para que essa oficina acontecesse, a presença de um estudante haitiano que quisesse trabalhar como professor voluntário. $\mathrm{O}$ aluno Olson Oscar foi o primeiro a se candidatar, porém havia dois empecilhos: o horário de trabalho do estudante e a escassez de professores que pudessem orientar o discente no planejamento das aulas.

Somente em 2019, foi possível colocarmos em prática essa oficina, que, inicialmente, foi planejada e implementada pelo estudante-professor Olson Oscar e pela segunda autora deste artigo. A ele, coube selecionar conteúdos que ele considerava importantes, enquanto a essa docente cabia pensar no material didático e na melhor estratégia de abordagem dos conteúdos escolhidos. Foi interessante percebermos, por meio das escolhas feitas por esse estudante-professor, que o que mais lhe importava era contextualizar: a imigração do Haiti para o Brasil; a historicidade do país; as conquistas realizadas a partir da Revolução Haitiana; aspectos culturais; a relação dos haitianos com suas línguas oficiais (o crioulo haitiano e o francês). O planejamento de aula do discente visava promover o orgulho da identidade haitiana e melhorar a comunicação entre os haitianos e os brasileiros.

Por isso, nos primeiros encontros das oficinas de crioulo haitiano, além de trabalharmos os cumprimentos, desenvolvemos atividades com foco na localização geográfica do Haiti, uma vez que os brasileiros frequentemente confundiam os haitianos com africanos. Também trabalhamos semelhanças e diferenças culturais e discorremos sobre o período escravocrata no Brasil e no Haiti. A ideia inicial era não só quebrar as barreiras linguísticas entre as pessoas, mas também combater a xenofobia que, muitas vezes, era expressa nas aulas. Sabemos que a EJA, em São Paulo, é formada, majoritariamente, por estudantes oriundos das regiões norte e nordeste do Brasil, e a reflexão proporcionada pela presença dos haitianos trouxe a tais discentes brasileiros a consciência de que eles também eram migrantes e que, às vezes, também passavam por situações xenofóbicas.

O estudante-professor Olson Oscar nos ensinou sobre a importância de se preservar e valorizar a sua própria língua em todos os espaços. Procurou mostrar, ademais, que o acesso à aprendizagem dessa língua adicional, para os brasileiros, facilitaria a comunicação e contribuiria para que houvesse maior empatia dos educandos brasileiros para com os haitianos, no sentido de perceberem as dificuldades que um migrante internacional vivencia em um novo país.

\section{Considerações finais}

Neste artigo, discorremos sobre o Centro Integrado de Educação de Jovens e Adultos (CIEJA), que consiste em uma das modalidades de EJA da rede pública municipal de São Paulo. Discorremos, também, sobre duas atividades extracurriculares desenvolvidas em um dos 16 
(dezesseis) CIEJAs da capital paulista: as oficinas de italiano e de crioulo haitiano.

Procuramos explicar, ao longo do texto, que o CIEJA é uma instituição educacional de inspiração freiriana e que, portanto, busca concretizar a ideia de que a educação é um direito de todos.

Ainda com base nos postulados de Freire (1974), procuramos esclarecer que as oficinas de italiano e crioulo foram propostas no CIEJA Perus I com o escopo de oferecer o acesso a línguas adicionais a todos, isto é, consideramos que aprender outras línguas seja um direito de todas as pessoas, e não somente daquelas que têm condições socioeconômicas que lhes permitem pagar por esses cursos.

Para ilustrar a relevância dessas oficinas para os participantes, transcrevemos ${ }^{5}$, a seguir, respectivamente, as opiniões de uma estudante brasileira (que discorreu sobre as duas oficinas) e de um estudante-professor haitiano (que discorreu acerca das oficinas de crioulo):

"Eu acho muito bom aprender um pouco de todas as línguas. É muito importante para a gente poder se comunicar com as pessoas, igual a gente estava aprendendo o crioulo para podermos nos comunicar melhor com os nossos amigos haitianos. E eu gostava da aula de italiano também, principalmente das músicas, que são muito bonitas e nos ensinam muitas coisas" (Maria Silva ${ }^{6}$, aluna brasileira que participava das oficinas de italiano e crioulo haitiano)

"As oficinas de crioulo são de grande importância para mim, porque é um prazer enorme ensinar ao grande povo brasileiro minha língua nativa, que é o crioulo. Nessas oficinas, brasileiros e haitianos confraternizam melhor. Eu gostaria que os brasileiros aprendessem o crioulo para que conhecessem a minha cultura e a história do Haiti, país que deveria ser mais conhecido por sua luta de humanidade, luta contra a escravidão, o colonialismo e o imperialismo" (Olson Oscar, estudante haitiano e ministrante das oficinas de crioulo do CIEJA)

Desde que a pandemia começou, nossas oficinas tiveram de ser interrompidas, mas fizemos algumas tentativas de organizar encontros remotos com os participantes de ambas as oficinas. Infelizmente, porém, tivemos a presença de apenas 8 (oito) discentes em tais encontros, porque a maioria dos alunos, por vivermos em um país marcado pela desigualdade social, não possui os recursos materiais necessários para participar de aulas online. Isso mostra que, devido a essa desigualdade, desvelada com força total durante a pandemia, infelizmente, o acesso a línguas adicionais passa a ser restrito, ou seja, somente o têm aqueles que dispõem das condições materiais necessárias para tal.

Diante de tudo o que foi exposto neste artigo, é possível dizer que as oficinas de italiano e crioulo haitiano, realizadas presencialmente no CIEJA Perus I, visam ser uma tentativa de deselitização do ensino-aprendizagem de línguas, o que pode ser visto como uma forma de

$5 \quad$ As opiniões transcritas acima nos foram enviadas pelos educandos por meio de mensagens de áudio no Whats App em dezembro de 2020.

$6 \quad$ Nome fictício. 
buscar justiça social (FREIRE, 1974). Todavia, enquanto a pandemia perdurar, a fim de que essas oficinas continuassem sendo acessíveis a todos, seria urgente que o poder público garantisse aos educandos as condições materiais necessárias (tablets, computadores e/ou celulares, internet etc.) para que eles pudessem participar dessas atividades extracurriculares a distância.

Dessa maneira, com este artigo, também pretendemos fazer uma denúncia contra o descaso do governo - em níveis municipal, estadual e federal - em relação à escola pública, a qual, desde o início da pandemia, vem sendo cada vez mais negligenciada, abandonada e marginalizada. Devido a esse descaso, infelizmente, a escola pública não tem conseguido cumprir seu papel principal, postulado pela Lei de Diretrizes e Bases da Educação brasileira e defendido por Freire (1974) e tantos outros autores: garantir o direito à educação a todos.

\section{Referências}

ALMEIDA, S. Racismo estrutural. São Paulo: Editora Pólen, 2019.

ARROYO, M. M. G. Passageiros da noite - do trabalho para a EJA: itinerários pelo direito a uma vida justa. Petrópolis: Vozes, 2017.

BAKHTIN, M. Discourse in the novel. In: HOLQUIST, M. (org.). The dialogic imagination. Austin: University of Texas Press, 1981, p. 259-422.

BAKHTIN, M.; VOLOCHINOV, V. N. Marxismo e filosofia da linguagem. São Paulo: Editora Hucitec, 1986.

BLOMMAERT, J.; BACKUS, A. Superdiverse repertoires and the individual. Current challenges for educational studies. In: SAINT-GEORGES, I.; WEBER, J. (orgs.). Multilingualism and multimodality. Boston: Sense, 2013, p. 11-32.

BRASIL. Ministério da Educação. Lei de Diretrizes e Bases da Educação Nacional, Lei no 9394/96. Disponível em: http://www.planalto.gov.br/ccivil_03/leis/19394.htm. Acesso em: 04 abr. 2021.

BUSCH, B. The linguistic repertoire revisited. Applied Linguistics. Oxford University Press, 2012, p. 1-22. DOI: 10.1093/applin/ams056

BUSCH, B. Linguistic repertoire and Spracherleben, the lived experience of language. Working papers in urban language and literacies. Paper 148, 2015. Disponível em: http://heteroglossia.net/filead$\mathrm{min} /$ user_upload/publication/WP148_Busch_2015_Linguistic_repertoire_and_Spracherleben-libre.pdf. Acesso em: 04 nov. 2021.

FIALHO, C. M. C.; VIEIRA, D. A.; FERREIRA, G. S. S. Qual o papel da EJA na informação e na formação em épocas de pandemia? In: LIBERALI, F. C.; FUGA, V. P.; DIEGUES, U. C. C.; CARVALHO, M. P. (orgs.). Educação em tempos de pandemia: brincando com um mundo possível. Campinas: Pontes, 2020.

FREIRE, P. Pedagogia do oprimido. Rio de Janeiro: Paz e Terra, 1974.

GEERTZ, C. Nova luz sobre a antropologia. Rio de Janeiro: Jorge Zahar, [1978] 2001.

LEFFA, V. J.; IRALA, V. B. O ensino de outras línguas na contemporaneidade: questões conceituais e metodológicas. In: LEFFA, V. J.; IRALA, V. B. (orgs.). Uma espiadinha na sala de aula: ensinando línguas adicionais no Brasil. Pelotas: Educat, 2014.

LIBERALI, F. C.; LIBERALI, C. C.; PADRE, B. T.; SANTOS, J. A. A. Mobilidade e práticas translíngues na construção de um mundo com justiça social: um estudo no projeto Digit-M-ed. In: ROCHA, 
C. H.; EL KADRI, M. S.; WINDLE, J. A. Diálogos sobre tecnologia educacional: educação linguística, mobilidade e práticas translíngues. Campinas: Pontes, 2017.

MAUGERI, M. Tutti pazzi per l'italiano, è quarta lingua più studiata. 2016. Disponível em: https:// www.agi.it/cultura/tutti_pazzi_per_litaliano_quarta_lingua_pi_studiata-1174983/news/2016-10-18/. Acesso em: 18 nov. 2020.

MENDES, E. A ideia de cultura e sua atualidade para o ensino-aprendizagem de LE/L2. Revista EntreLinguas, Araraquara, v. 1, n. 2, p. 203-222, 2015. Disponível em: https://periodicos.fclar.unesp.br/ entrelinguas/article/view/8060. Acesso em: 15 jun. 2021.

SÃO PAULO, SECRETARIA MUNICIPAL DE EDUCAÇÃO. Currículo da Cidade - Educação de Jovens e Adultos - Língua Portuguesa. São Paulo: SME, 2019.

SCHLATTER, M.; GARCEZ, P. Linguas adicionais na escola: aprendizagens colaborativas em inglês. Porto Alegre: Edelbra, 2012.

VIEIRA, D. A. Italiano para todos: o italiano como língua adicional em um Centro Integrado de Educação de Jovens e Adultos brasileiros e imigrantes. Revista Italiano UERJ, v. 10, nº 2, 2019, p. 116-135.

Recebido em: 07/04/2021 (versão atualizada: 19/06/2021)

Aprovado em: 27/07/2021 